\title{
EKSISTENSI ISTANA KERAJAAN DI KALIMANTAN BARAT SEBAGAI SUMBER BELAJAR SEJARAH
}

\author{
Yuver Kusnoto \\ Program Studi Pendidikan Sejarah IKIP PGRI Pontianak \\ email: yuver.kusnoto@yahoo.co.id \\ Haris Firmansyah \\ Program Studi Pendidikan Sejarah IKIP PGRI Pontianak \\ email : haris_eskabe89@yahoo.co.id
}

\begin{abstract}
Abstrak
Tulisan ini merupakan sebuah pemikiran yang bertujuan utuk memberikan wacana baru dalam pembelajaran. Khususnya yang berhubungan dengan masalah pemilihan sumber belajar bagi guru maupun siswa dalam belajar sejarah, terutama sejarah Lokal Kalimantan Barat. Justifikasi sejarah lokal Kalimantan barat tidak memiliki peluang untuk masuk dalam wacana sejarah nasional sering sekali muncul dipermukaan pada beberapa kali pembicaraan yang serius maupun obrolan warung kopi. Materi sejarah tidak hanya membicarakan tentang isu-isu nasional tetapi wacana sejarah daerah atau sejarah lokal juga memiliki posisi yang strategis untuk dijadikan sumber belajar sejarah, karena sejarah lokal dipandang lebih dekat dengan kehidupan siswa, sehingga nuansa kontekstual dalam pembelajaran akan lebih mengena tidak sebaliknya yang dirasakan selama ini abstrak. Untuk itu diperlukan tawaran-tawaran sumber belajar serta strategi yang dapat di tempuh untuk mewujudkan sebuah tujuan pembelajaran sejarah agar lebih efektif dan efisien.

Kata kunci: Eksitensi Istana, Sumber Belajar Sejarah, Pembelajaran Sejarah
\end{abstract}

\begin{abstract}
This research is a thinking that has aim to give a new discourse of learning. Especially, it has relation with the problem of source election of learning for the teachers and even for the students in learning history; particularly, local history of Kalimantan Barat. Justification of local histories in Kalimantan Barat have no opportunities to be a national discourse history which often appeared in a formal discussion or even in an informal discussion. Material of history not only talked about national issues, but as a discourse region history or local history which also have strategies position to be a source of learning history. It because local histories seemed more closed with students' life, so the contextal nuance in learning will be established, but on the contrary it's feel abstract. So, it's need to bargain for the learning source and also the strategy that could be gain to reach a history learning purpose and also to make it more effective and efficient.
\end{abstract}

Keyword: The existence of the Palace, Learning Resources, Learning History

\section{PENDAHULUAN}

Penemuan ilmiah terbaru saat ini memberitahu kita bahwa justru hubungan antara bagian-bagian tersebutlah yaitu konteksnya yang memberikan makna (Elaine $B$ Johnson) 
Masalah pembelajaran sejarah selalu saja unik untuk di perbincangkan. Pembicaraan mengenai pembelajaran sejarah sering kita temukan baik di forum-forum ilmiah seperti seminarseminar, workshop, pelatihan-pelatihan, diskusi-diskusi juga di berbagai macam tulisan, mulai dari hasil penelitan, jurnaljurnal ilmiah, majalah, koran, dan berbagai media lainnya. Isi pembicaraannya pun berbagai macam tema, mulai dari kurikulumnya, model dan metode pembelajarannya, sampai permasalahan sulitnya mencari sumber belajarnya. Yang paling sering ditemukan adalah pada akhir dari pembicaraanya berujung pada sebuah permasalahan yang sampai sekarang sulit untuk dipecahkan adalah diakhir proses pembelajaran sejarah bahwa ketika mendengar pelajaran sejarah maka yang pertama kali terlitas dibenak kita adalah pelajaran ini cenderung membosankan, kering, monoton, hafalan, dan segala bentuk kesan yang kurang menyenangkan, ditambah lagi penampilan guru yang pada waktu mengajar dengan penampilan seadanya, tidak menggunakan media pembelajaran yang menarik. Pembelajaran sejarah sering diidentikkan dengan kefasihan bercerita, mendongeng. Yang lebih memprihatinkan lagi adalah kondisi ini terjadi pada setiap jenjang pendidikan mulai dari sekolah dasar sampai perguruan tinggi.

Gejala-gejala negatif pembelajaran sejarah di atas tentu akan berbenturan ketika dihadapkan pada kondisi sekarang dimana konteks pembelajaran sejarah yang kaku dan cenderung monoton akan menutup pemikiran peserta didik yang seharusnya sudah menuju pada era keterbukaan atau era globalisasi. Tuntutan era globalisasi ini bila diletakan dalam posisi dan peran pendidikan maka impilikasinya adalah mindset berfikir pada setiap bidang, komponen lapisan dan jenjang pendidikan semuanya harus mengalami perubahan tak terkecuali proses pembelajaran sejarah yang terjadi di sekolah. Mata pelajaran sejarah adalah salah satu bagian dari kegiatan pembelajaran yang berlangsung di sekolah.

Pemberlakuan Kurikulum Tingkat Satuan Pendidikan memberikan peluang yang sangat besar kepada guru untuk mengembangkan kreativitasnya. Pemerintah melalui Badan Standar Nasional Pendidikan (BSNP) hanya membuat standarnya saja, yakni hanya menentukan standar kelulusan yang kemudian dijabarkan ke dalam standar isi yang memuat bahan kajian, mata pelajaran, serta kegiatan belajar pembiasaan. Kurikulum 2013 kemungkinan tidak akan mengubah orentasi dari 
pembelajaran sejarah untuk standar kebermaknaan tentang interpretasi peristiwa-peristiwa sejarah yang di muat dalam pembelajaran sejarah itu sendiri.

Ada sebuah gejala yang kadang dilupakan oleh lembaga-lembaga pendidikan dalam hal ini salah satunya adalah sekolah yang di dalamnya terdapat komponen-komponen yang salah satunya adalah guru, dimana peserta didik hanya mendapatkan proses pembelajaran di sekolah tidak lebih dari setengah hari. Selebihnya mereka berada di lingkungan keluarga dan masyarakat. Dua lingkungan ini sangat berpengaruh bagi peserta didik dalam hal perubahan pola fikir dan tingkah laku sehari-harinya.

Guru sebagai kreator dalam pembelajaran mestinya mampu memanfaatkan lingkungan tersebut sebagai sumber belajar dalam pembelajaran sejarah karena akan sangat membantu dalam memecahkan permasalahan-permasalahan tentang stigma negatif pembelajaran sejarah. Belajar sejarah berarti menggali lebih dalam tentang apa yang pernah ada dalam lintasan masa lalu dalam lingkungan tersebut, yang terlebih dahulu adanya ketersediaan medium untuk mengembangkan kepedulian dan ketertarikan akan ranah daerah atau lingkungan.
Ada banyak pemahaman tentang strategi pembelajaran yang di kemukakan oleh para ahli. Wina Sanjaya (2006:126) mengemukakan strategi pembelajaran adalah perencanaan yang berisikan tentang rangkaian kegiatan yang didesain utuk mencapai tujuan pendidikan tertentu. Kemp, Merisson, Dan Ross (1995:25) menjelaskan bahwa strategi pembelajaran adalah suatu kegiatan pembelajaran yang harus dikerjakan guru dan siswa agar tujuan pembelajaran dapat dicapai secara efektif dan efisien. Senada dengan pendapat ini, Dick and Carey (1985:167) juga menyebutkan bahwa strategi pembelajaran adalah satu set materi dan prosedur pembelajaran yang digunakan secara bersama-sama untuk menimbulkan hasil belajar pada siswa. Beberapa konsep tentang strategi pembelajaran ini memberikan pemahaman kepada pendidik maupaun peserta didik bahwa proses pembelajaran pada akhirnya akan melahirkan satu bentuk pemahaman yang utuh tentang tujuan yang ingin dicapai, sehingga diperlukan sumber-sumber belajar dalam rangka mencapai tujuan tersebut.

Tulisan ini mencoba menguraikan tentang ketersediaan sumber belajar sejarah. Sumber belajar merupakan sesuatu yang dapat membantu tiap orang untuk belajar menampilkan kompetensinya dan dapat digunakan 
untuk mendukung materi pembelajaran tertentu (Narwanti dan Somadi, 2012:68). Sedangkan menurut Sanjaya (2012:228) "Sumber belajar adalah segala sesuatu yang ada di sekitar lingkungan kegiatan belajar yang secara fungsional dapat digunakan untuk membantu optimalisasi hasil belajar". Alur penggunaan sumber belajar sejarah seperti di bawah ini

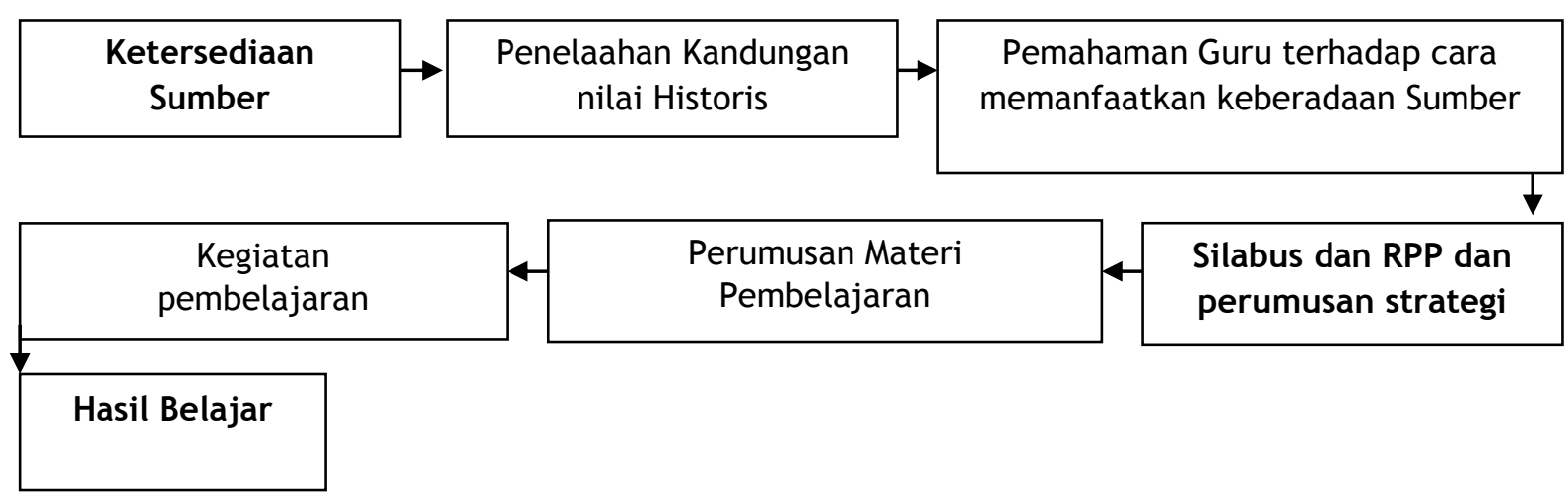

Gambar 1. Alur Penggunaan Sumber belajar dalam Pembelajaran

Salah satu sumber sejarah yang dapat digunakan sebagai sumber belajar adalah situs sejarah. Situs sejarah merupakan bukti eksistensi adanya suatu peradaban dimasa lalu, hal ini dapat dimanfaatkan secara efektif oleh seorang guru dalam mengajar, khususnya situs sejarah yang terdapat di daerah masingmasing karena dukungan lingkungan sangat menentukan proses pembelajaran.

Salah satu situs sejarah yang dapat dimanfaatkan oleh guru sebagai sumber belajar sejarah di Kalimantan barat adalah Istana Kerajaan. Eksistensi Istana Kerajaan adalah hal unik yang terdapat di Kalimantan Barat karena telah menunjukan dan membuktikan adanya Kerajaan-Kerajaan yang berdiri dan berdaulat yang kemudian membentuk dinamika sejarah yang barangkali berbeda dengan daerah-daerah lainya, Istana Kerajaan yang terdapat di Kalimantan Barat berjumlah 9 dimana semua istana Kerajaan tersebut berkembang pada zaman Islam. Keberadaan istana-istana ini menyimpan banyak persitiwa sejarah yang menyertainya. Perstiwa-peristiwa masa lampau yang terjadi di Istana-istana kerajaan ini tentu dapat tersampaikan dengan baik bila guru menguasai dan dapat memanfaatkan sumber balajar ini dengan baik.

Adapun Kerajaan-kesultanan yang memiliki Istana yang berkembang pada zaman Islam tersebut antara lain: Kerajaan Matan, Kerajaan Mempawah, 
Kerajaan Sambas, Kerajaan Landak, Kerajaan Tayan, Kerajaan Sanggau, Kerajaan Sekadau, Kerajaan Sintang, dan Kerajaan Pontianak. Dengan banyaknya berdiri Kerajaan-kesultana Islam di Kalimantan Barat mempengaruhi kebudayaan-kebudayan yang ada di masyarakat dan menjadikan Islam menjadi Agama yang mayoritas dianut oleh masyarakat Kalimantan Barat.

Adapun metode penelitian yang digunakan dalam penelitian ini termasuk penelitian dasar yang menekan pada objek dan fakta-fakta yang tampak yaitu sumber belajar sejarah lokal untuk sekolah-sekolah yang terdapat di Kalimantan Barat. penelitan ini dilaksanakan pada satu tempat dan fokus masalah yang dijadikan sasaran penelitan dan fungsi sumber belajar sejarah lokal yang dalam hal ini adalah Istana-Istana Kesultanan sebagai sarana pembelajaran sejarah lokal. Jenis penelitan ini lebih khusus disebut studi kasus tunggal terpancang atau embedded case study (Sutopo, 2006: 180).

\section{HASIL DAN PEMBAHASAN}

Keberadaan Istana Kerajaan di

\section{Kalimantan Barat}

1. Istana Kerajaan Matan-Tanjungpura Kerajaan Matan Tanjungpura sebelum zaman Islam kerajaan Ini sudah terkenal sebagai kerajaan terbesar di Kalimantan Barat. Kerajaan ini memiliki Istana Penambahan Kerajaan Matan G.M Saunan yang berlokasi di desa Mulia Kerta, Kecamatan Benua Kayong Ketapang, Kabupaten Ketapang. Di Istana ini kita dapat menjumpai peninggalan G.M Saunan yang sudah berumur ratusan tahun dan mempunyai legenda yang unik seperti meriam Padam Pelita yang diceritakan dibuat oleh mahkluk halus.

2. Istana Kerajaan Mempawah

Patih Gumantar merupakan cikal bakal dari kerajaan Kerajaan Mempawah yang memerintah sekitar abad ke XIV yang beribukota di Mempawah Hulu. Namun semenjak Upu Daeng Menambun ibu kotanya pada abad XVII dipindahkan ke Sebukit Rama, kemudian pada abad pertengahan (abad XIX) pada masa Gusti Jati/Sultan Muhamad Zainal Abidin pusat pemerintahan dibangun di Mempawah (Ibu Kota Kabupaten Mempawah sekarang). Di pusat kota inilah di dirikan Istana Kerajaan Mempawah yang dikenal dengan nama Istana Amantubillah. Istana Amantoebillah terletak di Kelurahan Pulau Pedalaman, Kota Mempawah, Kabupaten Mempawah. Jika berkunjung di Istana tersebut kita juga dapat melihat situs-situs sejarah 
sekitar kawasannya seperti Masjid Jami'atul Khair dan Makam Panambahan atau sultan-sultan dan kerabat Istana.

3. Istana Kerajaan Sambas

Kerajaan Sambas mulai dikenal sejak abad ke XVII dengan rajanya Sultan Muhammad Syaefudin I. Istana kerajaan sambas dikenal dengan nama Istana Alwatzikhoebillah, Istana yang terlihat sekarang ini baru dibangun pada masa pemerintahan Muhammad Mulia Ibrahim Syafiudin yang merupakan sultan ke 15 yang dibangun dari tahun 1931-1935. Istana Alwatzikhoebillah terletak ditempat yang strategis yakni berletak pada pertemuan Tiga Sungai, yakni Sungai Sambas Kecil, Sungai Subah dan Sungai Teberau.

4. Istana Kerajaan Landak

Raja pertama Kerajaan Landak adalah Raden Ismahayana yang setelah masuk agama Islam dikenal dengan gelar Abdulkhar. Istana Ismahayana landak terletak di Ngabang, Kabupaten Landak, Provinsi Kalimantan Barat. Di dalam lingkungan selain Istana juga terdapat Masjid Djami' Keraton Landak serta makam raja dan para kerabatnya.

5. Istana Kerajaan Tayan

Gusti Likar merupakan raja pertama dari Kerajaan Tayan, ia merupakan keturunan Brawijaya dari Majapahit. sedangkan raja terakhirnya (1960) adalah Gusti Ismail dengan gelar Panembahan Paku Negara. Istana Kerajaan Tayan sampai saat ini masih dalam kondisi asli dan terawat dengan cukup baik, Istana ini dibangun oleh Gusti Jamal. Jika kita berkunjung kesanan kita dapat melihat beberapa benda bersejarah yang terdapat di dalamnya antara lain meriam, keris, busana kerajaan dan sajadah sembahyang raja. Istana ini dapat ditemui di Tayan, 70 kilometer dari kota Sanggau, berlokasi dekat dengan sungai Kapuas.

6. Istana Kerajaan Sanggau

Kerajaan Sanggau memilki dua Istana pada masa berdiri pada masa yang berbeda, hal itu disebabkan pengaruh kolonial. Yang pertama, Istana Kuta adalah bangunan utama sebagai simbol kekuasaan Kesultanan Kuta, dimana digunakan untuk aktifitas Kesultanan ataupun tamu Sultan. Kedua, Istana Beringin, usia bangunan yang relatif muda dibandingkan dengan istana Kuta, mengingat terbentuknya Istana akibat dari sistem pemerintahan Belanda (abad 18) pada saat itu yang ingin mendapatkan kekuasaan mutlak melalui pihak istana.

7. Istana Kerajaan Sekadau 
Kerajaan Sekadau awalnya berpusat di Keluaten kemudian dipindahkan ke Sekadau di Kampung Sungai Baru. Raja-raja yang memerintah kerajaan ini adalah keturunan Prabu Jaya dan keturunan Raja-raja Siak Bulun.

Secara fisik bangunan Istana Kerajaan Sekadau sudah tidak ditemukan lagi, yang ada hanya berupa tiang-tiang/kolom-kolom yang sangat tinggi. Komplek Istana berada di Desa Mungguk, di sekitar komplek juga terdapat Masjid At-taqwa dengan kondisi masih baik namun sudah berubah dari bentuk aslinya.

8. Istana Kerajaan Sintang

Kerajaan Sintang merupakan perkembangan dari kerajaan Sepauk, yang ada sebelum kedatangan Agama islam dan pernah tersohor pada masa pemerintahan Aji Melayu dan permaisurinya Putung Keempat. Baru pada pemerintahan Demong Irawan yang bergelar Jubair I pusat pemerintahan dipindahkan ke Sintang.

Kawasan Istana Sintang secara admnistratif terletak di desa Kapuas Kiri Hilir, Kecamatan Sintang, Kabupaten Sintang, Prifinsi Kalimantan Barat. Bangunan Istana ini direncakan oleh arsitek Belanda, konstruksi bangunannya ditegakkan pada tahun 1937 pada masa
Panembahan Raden Abdul Bahri Danu Perdana.

9. Istana Kerajaan Pontianak

Kerajaan Pontianak didirkan oleh Syarif Abdurahman pada tanggal 23 Oktober 1771. Syarif Abdurahman adalah keturunan/anak Alhabib Husin pemuka Agama Islam dari Negeri Arab. Istana Kadriah didirkan oleh pendiri kerajaan terbentuknya istana tersebut pada tahun 1778 bersamaan dengan dilantiknya beliau menjadi Sultan Pontianak. Istana Kadriah terletak dikawasan yang menjadi cikal bakal berdirinya Kota Pontianak (Kampung Beting) yakni di penghujung pertemuan dua sungai (sungai kapuas Kecil dan sungai landak) dimana letak Istana dan Masjid Jami' berada satu garis dengan sungai Kapuas yang mengarah ke muara sungai.

\section{Strategi Pembelajaran yang Dapat Digunakan}

Guru sejarah di dalam pembelajaran selalu dihadapkan dengan berbagai masalah, Salah satunya adalah rasa bosan yang selalu dirasakan oleh peserta didiknya dalam mengikuti pembelajaran sejarah, hal ini dapat membuat pembelajaran sejarah tidak berjalan efektif dan tidak efisien. Oleh sebab itulah guru sejarah selalu dituntut kreatif dalam merencanakan dan 
melaksanakan pembelajaran sejarah guna mengatasi permasalahan tersebut, sehingga tujuan pembelajaran sejarah dapat tercapai.

Pemanfaatan eksistensi Istana Kerajaan di Kalimantan Barat sebagai sumber belajar dari lingkungan peserta didik menjadi strategi pembelajaran yang dapat digunakan oleh guru sejarah, dimana selama ini telah banyak diabaikan oleh guru karena pembalajaran masih terfokus dengan metode ceramah di dalam kelas tanpa memanaafatkan media pembelajaran yang ada.

Adapun strategi pembelajaran yang memanfaatkan sumber belajar tersebut adalah sebagai berikut :

1. Strategi pembelajaran melalui Karya Wisata

$$
\begin{aligned}
& \text { Sudah selayaknyalah } \\
& \text { pembelajaran harus lebih variatif, } \\
& \text { sehingga pembelajaran sejarah yang } \\
& \text { di dalam kelas tidak membosankan } \\
& \text { dan kering. Sesekali pembelajaran } \\
& \text { sejarah harus dilaksanakan di luar } \\
& \text { kelas, siswa diajak untuk melihat hal- } \\
& \text { hal sekitar daerah tempat mereka } \\
& \text { tinggal yang berkaitan dengan tempat } \\
& \text { tertentu atau objek lainya dalam hal } \\
& \text { ini adalah Istana-istana kerajaan yang } \\
& \text { ada di Kalimantan Barat. } \\
& \text { Pembelajaran seperti itu } \\
& \text { dapat memanfaatkan strategi } \\
& \text { pembelajaran melalui Karya Wisata. }
\end{aligned}
$$

Strategi pembelajaran melalui karya wisata dapat membuat materi sejarah yang dipelajari lebih relevan dengan kenyataan dan kebutuhan yang ada di masyarakat, selain itu juga dapat merangsang kratifitas siswa.

Karya wisata tidak hanya berkunjung liburan namun siswa diajak belajar demi memperluas pengetahuannya dengan melihat kenyataan langsung dilapangan, selain itu karya wisata dapat dirancang oleh guru untuk membuat siswa lebih aktif mencari sumber belajar secara langsung dengan meminta siswa membuat laporan dan kemudian didiskusikan ketika kembali ke kelas nantinya. Dengan berkunjung ke Istana-istana kerajaan yang ada di Kalimantan Barat siswa dapat melihat banyak peninggalan-peninggalan sejarah lainya serta bagaimana perjalanan sejarah kerajaan-kerajaan tersebut.

2. Strategi Pembelajaran Melalui Media Film

$$
\begin{aligned}
& \text { Perkembangan Tekhnologi } \\
& \text { memberikan pengaruh bagi dunia } \\
& \text { pendidikan. Sehingga guru selalu } \\
& \text { dituntut untuk meningkatkan } \\
& \text { kompetensinya sebagai pendidik yang } \\
& \text { memiliki kemampuan dalam } \\
& \text { memanfaatkan tekhnologi. }
\end{aligned}
$$


Strategi Pembelajaran Melalui Media Film merupakan salah satu dari model pembelajaran yang memanfaatkan tekhnologi sebagai media pembelajaran. Istana-istana Kerajaan Kalimantan Barat sebagai sumber belajar sejarah dapat dijadikan oleh guru objek film yang akan diajarkan di kelas. Film tentang Istana-istana Kerajaan Kalimantan Barat dapat memberikan pengalaman dasar dalam membaca dan berdiskusi sehingga mereka tertarik akan materi sejarah, selain juga dapat membantu proses pembelajaran yang dapat disaksikan berulang-ulang bahkan dilakukan oleh siswa sendiri di rumahnya.

3. Strategi pembelajaran melalui Media Maket

Strategi pembelajaran banyak yang dapat digunakan oleh guru, selain dengan wisata sejarah dan memanfaatkan media film sebagimana yang telah dibahas pada sub bab sebelumnya, guru juga dapat menggunakan media maket. Media maket merupakan bentuk tiga dimensi yang meniru sebuah objek yang dapat merepresentasikan dari keadaan sebenarnya. Menghadirkan Istana-istana Kerajaan Kalimantan Barat sebagai sumber belajar di dalam kelas dalam bentuk maket tentu dapat meningkatkan motivasi belajar siswa karena dapat merangsang tumbuhnya perhatian serta mengembangkan keterampilan siswa.

\section{PENUTUP}

\section{Simpulan}

Terdapat beberapa tempat bersejarah di Kalimantan Barat yang dapat digunakan sebagai sumber pembelajaran sejarah. beberapa tempat tersebut yakni Istana Kerajaan MatanTanjungpura, Istana Kerajaan Mempawah, Istana Kerajaan Sambas, Istana Kerajaan Landak, Istana Kerajaan Tayan, Istana Kerajaan Sanggau, Istana Kerajaan Sekadau, Istana Kerajaan Sintang, Istana Kerajaan Pontianak. Keberadaan tempattempat ini mendukung terhadap pembelajaran sejarah kontekstual. Adapun strategi pembelajaran yang cocok adalah Strategi pembelajaran melalui Karya Wisata, Strategi Pembelajaran Melalui Media Film, Strategi pembelajaran melalui Media Maket.

\section{DAFTAR PUSTAKA}

Kemp, J.E dkk. 1995. Designing effective instruction. New York: Macmillan College pulishing Company.

Narwanti dan Somadi. 2012. Panduan Menyusun Silabus dan Rencana Pelaksanaan Pembelajaran. Yogyakarta: Familia. 
Sanjaya, Wina. 2006. Strategi pembelajaran yang berorientasi pada standar proses pendidikan. Jakarta: Kencana.

. 2012. Perencanaan dan Desain Sistem Pembelajaran. Jakarta: Kencana.

Sutopo, HB (2006). Metodologi Penelitian Kualitatif. Surakarta: Universitas Sebelas Maret Press.

Walter, Dick dan Lou, Carey. 1985. The systematic design of instruction. New York: Harper Collins Publisher. 